\title{
Efficacy of Green Roof Technology in Colder Climates
}

\author{
Yancey Corden* \\ Northern Alberta Institute of Technology, Canada
}

\begin{abstract}
Green roof technology has been used within Canada as early as the first French settlers (1600) in the provinces of Nova Scotia and Newfoundland for necessity and survival in the Canadian wilderness. As home construction became more modernized, green roof technology was replaced by conventional roofing on houses and businesses. However, with the increased awareness of sustainable practices and environmental conservation, several European companies introduced new green roof technologies in the 1980s that began the movement of using this technology. While this technology has primarily been used in mild climates throughout Canada (Vancouver, British Columbia), little has been examined and researched regarding the use of green roof technology in colder and more severe climates within Canada. In his final year to complete his Bachelor Degree in Technology at the Northern Alberta Institute of Technology, Yancey Corden conducted research on the efficacy of green roof technology in Edmonton, Alberta capital region's cold and severe climatic conditions. The results suggested that native plants to the region are most successful when used in green roof technology.
\end{abstract}

\section{Green Roof Technology}

While green roofs in Canada were used as part of home construction design as early as the first French settlers (1600s) in the provinces of Nova Scotia and Newfoundland, 
green roof technology has remained a less viable option for Canadians until the early 1990s when "several large European green roof manufacturers started to venture into the North American markets" (Peck \& Kuhn, 2004). Green roof technology has been slowly embraced and implemented within Canada, with various architects and engineers promoting their uses and benefits. This article provides information about green roof technology, explains the benefits of this technology, and then describes a study conducted by a team of students in the Edmonton, Alberta, Canada region on the effects of green roof technology and plant species.

\section{What is a green roof?}

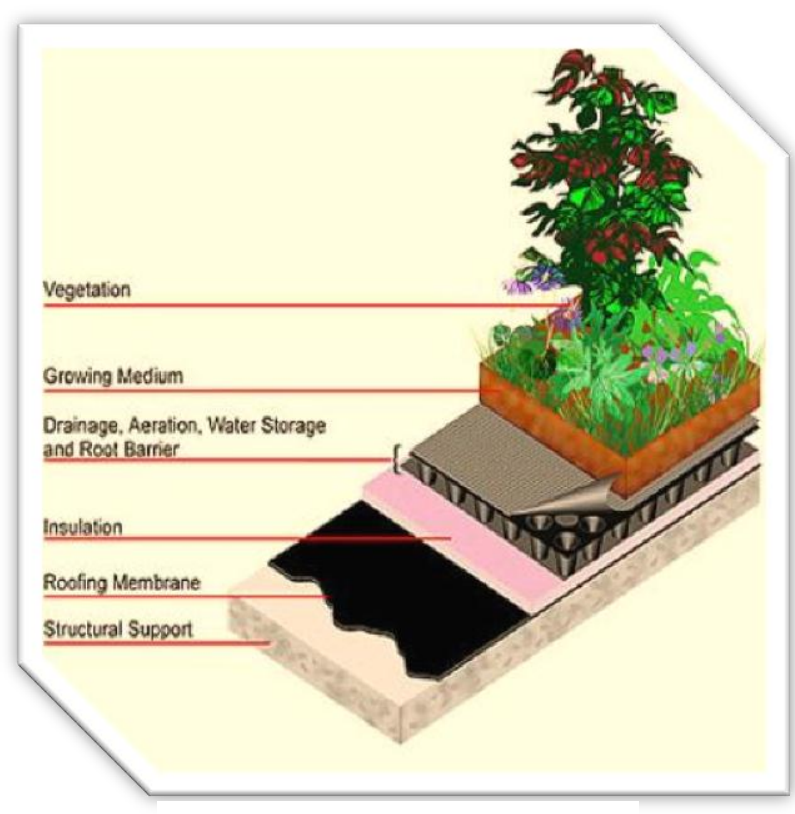

Figure 1: Green Roof Layers

A green roof is defined as being any roof of a building that is partially or completely covered with vegetation, and a growing medium (generally soil), which is planted over a waterproofing membrane. It may also include additional layers such as a root barrier, drainage, and irrigation systems (Toronto, 2011). The illustrated diagram (Figure 1: Green Roof Layers) shows an example of the typical layers of a green roof. Green roofs are generally classified in two categories related to their implementation: retrofit roofs, and new roofs.

Retrofit roofs entail taking an existing building and utilizing green roof technology, along with the buildings' existing structural load capacity, to create a suitable green roof. New roofs are installed on new buildings where the green roof is included in the design specifications. New green roofs are subject to substantially less structural constraints on the overall design, which enables easier upfront cost estimations. It should be noted that green roofs are unique in design and cost. There are no two alike. All load factors placed on the building have to be considered carefully, including the climate that the roof is located in, and the amount and type of precipitation that accumulates in that 
environment. Failure to consider the load factors could result in the unthinkable for a green roof developer -- a roof collapsing due to the additional weight of the green roof (Toronto).

\section{Benefits of a Green Roof}

Constructing a green roof increases the insulation value of that building (Wark \& Wark, 2003). This is a benefit in both the summer and winter months. Green roofs also help combat the phenomenon known as the urban beat island effect (Patel, 2011). As a result of urban heat island effect, temperatures on rooftops in the downtown Edmonton core on a warm summer's day are in the range of $50^{\circ}$ Celsius, much greater than the ambient temperature on such a day. Using the same example, when a green roof is employed on these same buildings, the rooftop temperatures would be the same as the ambient temperature of that particular day, approximately $25^{\circ}$ Celsius. The overall outcome as a result of this urban heat island effect is that the heat at these rooftops radiates downwards through the buildings and to the streets below. This equates to as much of an increase as two or three degrees Celsius. As the temperatures rise, buildings compensate with greater use of air-conditioning units, resulting in higher energy costs. When a green roof is utilized, this effect - and its resulting costs - is negated. In the wintertime, these same buildings are forced to pay for substantial heating costs as well. This is because buildings, much like the human body, lose large amounts of heat through the roofs. If these same buildings have a green roof installed, they are essentially wearing a green toque and retaining that heat which would otherwise be lost. The cost savings from such efforts can be substantial.

Another benefit of having green roofs in Edmonton is the wastewater management that is provided by the plants themselves. Wastewater is a term which includes all precipitation that encounters a building's roof on an annual basis (MassGov, 2011). One might not think this is a problem. However, it must be realized that all this wastewater has to be treated, and at a cost. The precipitation drains off the roof, runs into the storm sewers, and then goes to a facility for treatment. This volume is constantly calculated based on the square footage of the property, and the owner is billed accordingly. Green roofs are credited with utilizing up to $90 \%$ of all wastewater, another cost savings (MassGov).

Green roofs offer other benefits that are not initially seen in the cost benefits analysis. There is the aesthetic appeal when one looks out of an office window and sees a thriving green roof that can be accessed for lunchtime getaways. In addition, green roofs 
help reduce carbon dioxide levels that accumulate during peak traffic patterns in urban cores. This translates into a greener and cleaner environment. There is also the biodiversity that green roofs bring to the urban core. This is in the form of plant species, bees, birds, and various other environmentally beneficial creatures that the public now realizes are integral to the overall healthy existence of any productive biosphere.

However, understanding the basic structures, principles, and benefits of green roofs is only one level of knowledge that can be gained regarding this technology. Establishing a deeper comprehension of how green roof technology is applied and implemented is another area that can be explored. With a strong sense of curiosity and the need to know more, three fourth-year students from the Northern Alberta Institute of Technology (NAIT) were compelled to research how local plant species that thrive in the varied and sometimes extreme climate of Edmonton are affected when grown in a green roof environment. A detailed description of their research project follows.

\section{A Study on the Efficacy of Green Roof Technology in Colder Climates in the Edmonton Capital Region}

\section{Background}

This study derives from my (Yancey Corden) recent completion of a Bachelor of Technology Degree (BTech) at the Northern Alberta Institute of Technology (NAIT) in Edmonton, Alberta, Canada. In the final year of studies for this program, the students were asked to choose a subject for their Capstone Project. This yearlong course began as

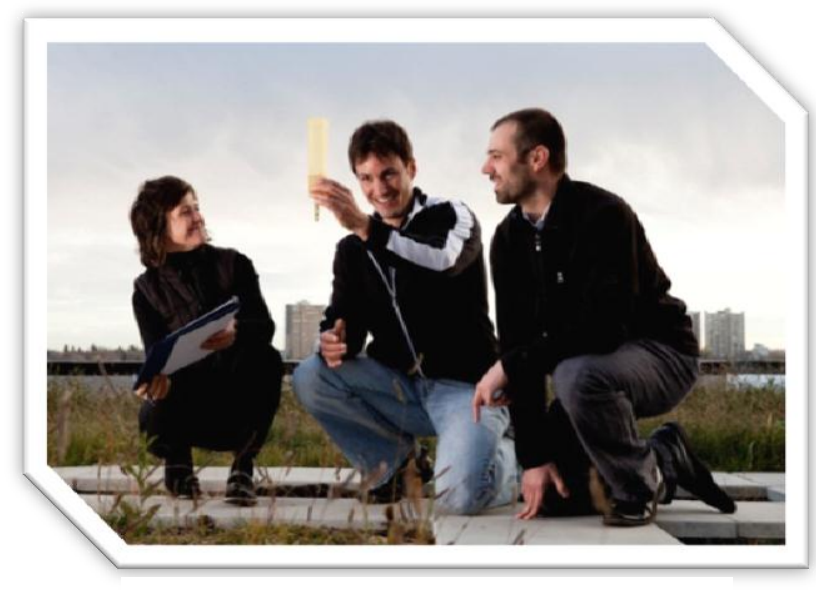

Figure 2: Student Research Team Members a labour intensive research exercise, and culminated with presentations given to a doctorial panel of judges, as well as members of the local business community. I chose a sustainability-based Capstone Project in an area of knowledge that was new to me: Keeping Green Roofs Green in the Capital Region (2011). This project appealed to me because it dealt with changing certain perceptions in Edmonton regarding green roofs and 
the interest in creating a more sustainable urban landscape as an integral part of the development process. The study included three researchers: Yancey Corden, Ryan Boyd, and Ruth Bucknell (Figure 2: Student Research Team Members).

\section{Purpose of the Study}

The recognition of greening roofs as a feasible approach to improving urban sustainability has been on the rise in North America over the last decade (Press, 2006). There is, however, the perception that green roofs are feasible only for mild humid climates. Canada is a large and diverse country that is divided into zones identifying and describing the different climates that affect plant growth. For example, Vancouver, British Columbia has an 8A climate zone (warm and moist). In comparison, Edmonton, Alberta has an extreme climate condition with a $3 \mathrm{~A}$ zone (dry and cold). This fact might affect the establishment and survival of plants used for green roofs in this zone. Winter survival studies are limited with respect to the climatic conditions experienced in the Edmonton region. The research team deemed it critical to know which plant species will survive in Edmonton's plant hardiness 3A zone (CanadaGov, 2011).

Therefore, the noted Capstone Project study was initiated in 2010 to observe the winter survival of plant species native to the Edmonton region which were grown on three green roofs. The three green roofs, each established in 2009-2010, were and continue to be located at the Williams Engineering (WE), Edmonton Waste Management Centre of Excellence (EWMC), and Esak Consulting Ltd. (EC) buildings.

\section{Nature of the Study and Procedures}

The study included one winter survival experiment per roof, each designed to determine a specific factor. The WE experiment was focused on determining if selected substrate (soil) depths affected winter survival; the EWMC experiment sought to determine if selected types of substrate (different soil mixtures with varying percentages of compost) and straw banking affected winter survival; and the EC experiment was created to determine if saturating the substrate with water affected winter survivability. Plant samples were taken from each green roof at four-week intervals (September 2010 to April 2011) and re-potted indoors, where growth rate and survival was monitored (weekly) by students at W.P. Wagner High School (located in the Edmonton Region). 


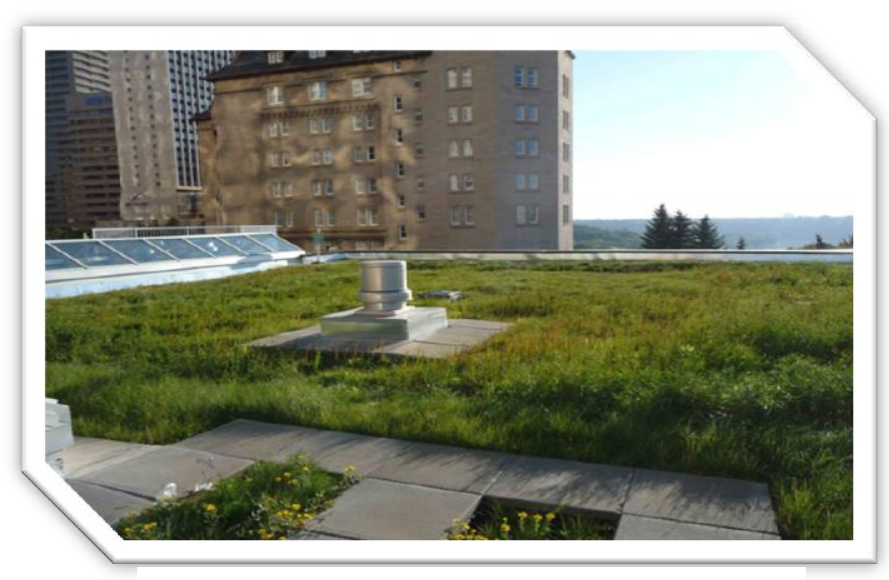

Figure 3: The William Engineering Green Roof
The plant samples for the study included seventeen species in total. This included ten forbs species (flowering plants), six grass species, and one sedge species (grass-like plant). An example of some of these species is shown in Figure 3: The William Engineering Green Roof (2010).

\section{Results}

The WE plants grown in a $10 \mathrm{~cm}$ medium (soil) were most successful. Initially, this result seemed incongruous when compared against previous results, since there was 7.5 $\mathrm{cm}, 10 \mathrm{~cm}$, and $12 \mathrm{~cm}$ growth mediums being used. It was assumed that the $12 \mathrm{~cm}$ medium would yield the best results. However, it was later determined that the samples appeared to be affected by the depth of medium in which the plants grew prior to sampling, which was similar to $10 \mathrm{~cm}$. The plants at the EWMC roof were not affected by the different mediums. In addition, the straw banking did not appear to give those samples an observable advantage over the other non-covered samples. Finally, the plants removed from EC's water saturation treatments did not survive the winter, likely because the plants had effectively drowned in the initial phase of the experiment. Overall, observations indicated that grasses native to the region survived better than forbs in a 3A zone (Corden, Boyd, \& Bucknell, 2011).

The study effectively demonstrated that green roofs survive the harsh winter climactic conditions that exist in the Edmonton area. Surprisingly, the WE roof study determined that the deepest medium was not in fact the best option. This is a successful finding; it means that shallower growth medium can be successfully utilized in Edmonton. This will help reduce the overall weight factor that is associated with the future implementation of green roofs in this region. This finding is most promising when looking at retrofit installations and the structural integrity issues that arise with these projects. 
It should also be noted that the 2010/2011 winter in the Edmonton region was not a typical winter. The snowfall was greater than normal, and the overall environmental conditions during the study period were not ideal. For a more effective base line, the team recommended that this study continue to progress over a further period of two to three years, in order to truly measure the data. However, this study did have positive outcomes, noted above, and did lay groundwork for future studies with green roofs in the Edmonton region.

This Capstone Project study helped create awareness about the makeup of green roofs and how they benefit urban areas. As with any new venture, a cost base analysis for a proposed green roof should be undertaken prior to development. Green roofs cost on average one and a half times more to install than a traditional flat top roof does, and as previously noted, each green roof is unique. Therefore, the associated implementation costs are not always easy to estimate. This is largely due to the fact that many are retrofit installations. With retrofit roofs, there are hidden costs that can arise, such as structural loading capabilities of an existing roof, which could require additional work and funds. However, many positive benefits offset these costs when considering green roofs. One of the key factors to consider is that a green roof lasts, on average, one and a half times longer than its traditional counterpart does. This is of great importance when one looks to green roofs for future development with sustainability in mind.

\section{Future Research}

It is the author's hope that the business community of Edmonton will collaborate with innovative institutions like NAIT and continue to look into green roof technology to foster its expansion and growth. There are hurdles to overcome, and knowledge gaps to be filled. However, this study was a positive first step to the creation of a more sustainable and greener Edmonton.

* Author: Originally, from British Columbia, Yancey Corden moved to the Edmonton region several

years ago. A graduate from the British Columbia Institute of Technology in Aircraft Mechanical Engineering in 1996; he pursued a career in aviation for many years. Yancey returned to school at the Northern Alberta Institute of Technology where he received his Bachelor's Degree in Technology in 2011. He is now attending Simon Fraser University in Vancouver where he will receive his MBA. Yancey has always been a nature enthusiast. He believes strongly in sustainability; as he works to meld his ideals with business, striving to find a balance between People, Planet, and Profit (Fisk, 2010). This 
is known as the triple bottom line in industry. It is aimed at the creation of a more balanced approach to business. One in which an equal weighting is placed on all three components by managers and stakeholders alike. These ideals help improve current business environments and help to bring about long-term sustainability.

\section{References}

CanadaGov. (2011). Plant hardiness zones in Canada. Retrieved August 7, 2011, from Agriculture and Agri-Food Canada:

http://sis.agr.gc.ca/cansis/nsdb/climate/hardiness/intro.html

Corden, Y., Boyd, R., \& Bucknell, R. (2011). Keeping Green Roofs Green in the Capital Region. Edmonton: NAIT.

Fisk, P. (2010). Planet, People, Profit. London: Kogan Page.

MassGov. (2011). Water, wastewater \& wetlands. Retrieved August 7, 2011, from MassDEP: http://www.mass.gov/dep/water/wastewater/grnroof.htm

Patel, N. (2011). U.S. EPA Heat Island Reduction Program. Washington, DC, USA.

Peck, S., \& Kuhn, M. (2004). Design guidelines for green roofs. Ontario Association for Architects.

Press, T. A. (2006). Landscape architects tend to a green roof . Retrieved March 2, 2011, from US News: http://www.msnbc.msn.com/id/12512892/ns/us_newsmsnbc_wire_services/

Toronto, C. o. (2011). What is a green roof? Retrieved August 7, 2011, from Toronto: http://www.toronto.ca/greenroofs/what.htm

Wark, C., \& Wark, W. (2003). Green roof specifications and standards. The Construction Specifier, pp. 1-12. 